\title{
PROTÓTIPO PARA CAPTAÇÃO, TRATAMENTO E USO DE ÁGUAS PLUVIAIS EM RESIDÊNCIAS URBANAS
}

\section{PROTOTYPE FOR RAINWATER CAPTATION, TREATMENT AND USE IN URBAN RESIDENCES}

\author{
Matheus Müller ${ }^{1}$, Márcia Regina de Freitas ${ }^{2}$, Daniel Clemente Vieira Rêgo da Silva ${ }^{3}$ \\ ${ }^{1}$ Mestre em Engenharia Civil, ITA Instituto Tecnológico de Aeronáutica, São José dos Campos, SP, Brasil, mrlmuller@gmail.com \\ 2 Pós doutora em Engenharia Civil, UNESP Universidade Estadual Paulista "Júlio de Mesquita Filho", Guaratinguetá, SP, Brasil, \\ marcia.freitas@unesp.br \\ ${ }^{3}$ Doutor em Ecologia, UNIFESSPA Instituto de Estudos do Xingu, São Félix do Xingu, PA, Brasil, daniel_cruzeiro@yahoo.com.br
}

\section{Resumo}

A água é um dos recursos de maior importância ao ser humano, tanto em questões fisiológicas quanto econômicas, ditando a saúde de um povo e possibilitando o desenvolvimento de uma nação. Por ser um bem de grande importância, é estranho o descaso que recebe, sendo poluída, exaurida e mal cuidada. O ciclo da água em centros urbanos já é comprometido, tanto pela alta taxa de impermeabilização do solo, quanto pela ocupação indevida de áreas de leito de rios. Por causa desses somados a outros fatores, em meados de 2014 a região Sudeste sofreu grande escassez deste recurso, tendo dificuldade de supri-lo, com seus reservatórios em níveis baixíssimos. Destaca-se então que o uso de água pluvial é uma real possibilidade ao meio urbano, com grande concentração de superfícies de coleta, podendo representar uma significante economia de água retirada dos mananciais para posterior tratamento, visando a potabilidade quando necessária. Neste trabalho é determinado o dimensionamento de um sistema de coleta, armazenagem e uso pluvial, explorando sua implementação na região metropolitana de São Paulo, e propondo melhorias por meio do desenvolvimento de um protótipo inovador de tratamento e disposição deste recurso. Visa-se então sua aceitação pela população e apoio em sua difusão pelo setor público, através de incentivos e afins, esperandose alcançar melhorias na problemática da água no país e no mundo.

Palavras-chave: Água pluvial. Economia. Superfícies de coleta. Sistema de coleta. Protótipo.

\begin{abstract}
Water is one of the most important natural resources for human beings, for physiological and economical reasons, enabling and sustaining life and promoting the development of nations. Being a resource of great importance, it is strange the disregard it receives, being polluted, exhausted and unkempt. The water cycle in urban centers is already compromised, both by high soil sealing rate and by improper occupation of riverbed areas. Because of these and other factors, in mid-2014 the Southeast region suffered great shortage of this resource, with its reservoirs at very low levels. The use of rainwater is a real possibility in the urban environment, using several surfaces for harvesting it. This is an opportunity for saving water from other water sources and mitigating its treatment requirements, aiming potability. This article discuss the design of a collection, storage and rainwater use system, exploring its implementation in the metropolitan region of São Paulo, proposing improvements through an innovative prototype development for treatment and disposal of this resource. The focus is then the acceptance of the system by the population and its diffusion support by the public sector, through incentives and related measures, aiming to achieve improvements in the water problems in Brazil and in the world.
\end{abstract}

Keywords: Rainwater. Saving. Surfaces for harvesting rainwater. Rainwater use system. Prototype. 
How to cite this article:

MULLER, M.; FREITAS, M.R.; SILVA, D.C.V.R. PROTÓTIPO PARA CAPTAÇÃO, tratamento E USO DE ÁGUAS PLUVIAIS EM RESIDÊNCIAS URBANAS. Interação, Varginha, MG, v. 22, p. 55 - 71, 2020. ISSN 1517-848X / ISSN 2446-9874.

Disponível em: http://periodicos.unis.edu.br/index.php/interacao/article/view/286.

DOI: https://doi.org/10.33836/interacao.v22i1.286

\section{INTRODUÇÃO}

A humanidade vem atingindo muitas conquistas em relação ao desenvolvimento tecnológico, mas para haver avanço são necessários insumos, dentre eles, um dos mais importante é a água. Este recurso natural é utilizado na maioria dos processos e áreas de atuação como agropecuária, indústria e fornecimento à população, sendo que sua disponibilidade e qualidade são indispensáveis ao crescimento de uma nação.

Infelizmente, este insumo é tratado com mediocridade, pois apesar das inúmeras crises e problemas, o ser humano ainda insiste em tratar este recurso como infinito, poluindo-o e desperdiçando-o de diversas formas (CAMPOS, 2004). Perante este cenário recorrente, já existiram diversas situações em que houve redução e até mesmo falta deste insumo, acarretando insuficiência de fornecimento e consequente inacessibilidade deste bem por parte da população. Esta situação precária só tende a se agravar, uma vez que a população do planeta é crescente, o recurso é finito e na sua administração não há o efetivo cuidado para que não haja problemas de abastecimento. Assim, estima-se que diversos países, dentre eles o Brasil, sofrerão com crises de falta de água e terão o desafio de fornecer água potável a suas populações (GHISI, 2006).

Sabe-se que a grande maioria do planeta é coberto por água, correspondendo a $71 \%$ de sua superfície, mas que apenas $4 \%$ deste montante é representativo da água doce, e destes, apenas uma pequena parte se encontra no estado líquido (USGS, 2019).

O Brasil possui aproximadamente $12 \%$ da quantidade de água doce líquida do mundo (TUCCl; HESPANHOL; NETTO, 2001). Apesar disso, devido ao seu crescimento demográfico, urbano e industrial, aliado à falta de consciência da população, culmina na apropriação indevida de seu solo, impermeabilização excessiva de suas cidades, poluição de seus mananciais e corpos de água superficiais, entre outros, tornando seus recursos hídricos comprometidos e insuficientes (JAQUES, 2005).

Esta situação arriscada, com a qual o país lida em relação a seus recursos hídricos, mostrou seus frutos em meados de 2014, onde foi possível se observar o início de uma crise que assolou o país, principalmente na região Sudeste (OLIVEIRA FILHO, 2015). Isto culminou em reservatórios com quantidades de água críticas e insuficientes, como o caso dos reservatórios do sistema Cantareira, principal provedor de água de São Paulo (MARTINS et al, 2014). Como resultado, setores como o de abastecimento de água e eletricidade ficaram fragilizados, demonstrando falha de administração e planejamento por parte do governo e órgãos competentes.

As crises hídricas não ocorrem apenas por falhas de gerenciamento, apesar de certamente serem agravadas por estas, mas também por fatores naturais, como mudanças climáticas, afetando o índice pluviométrico nas concentrações urbanas e, consequentemente, o nível de seus reservatórios (VIOLA; NUNES; FREITAS, 2007). Assim, uma possível solução para amenizar a problemática de disponibilidade quantitativa de água é o armazenamento e uso de água pluvial para finalidades não potáveis (GHISI, 2006), reservando a água potável a finalidades mais nobres, como a dessedentação. 
Assim, a coleta e uso de água pluvial em meio urbano, para finalidades onde não seja necessário o uso de água potável, é uma real alternativa para a redução da demanda deste bem, poupando os recursos hídricos naturais e a demanda de fornecimento do sistema público de abastecimento (COHIM; GARCIA; KIPERTOK, 2007).

Hoje a prática de aproveitamento pluvial é incentivada por diversos países no mundo, repercutindo a ideia de conservação deste recurso e, além disso, proporcionando outros fatores benéficos como a prevenção de enchentes, que é um acontecimento recorrente da alta taxa de impermeabilização do solo e ocupação indevida de áreas de várzea nas cidades. Contudo, mesmo proporcionando melhorias, esta prática ainda não possui incentivo no Brasil, não havendo colaboração ou interesse significativos por parte das concessionárias de água e esgoto (TOMAZ, 2003). Apesar disto, esta demonstra ser uma técnica com valor a ser explorada e desenvolvida, atingindo exequibilidade econômica e executiva, ao ser difundida por todo o país.

Neste contexto, este artigo apresenta um protótipo para captação e tratamento de água pluvial, possibilitando seu uso para atividades que não necessitem de água potável em residências urbanas. Gera-se, assim, uma economia de água potável em atividades diárias em que esta é indispensável. Para tanto, cálculos de capacidade de armazenamento de água pluvial para suprimento de uma residência média será demonstrado, bem como o projeto para a construção do coletor de água pluvial. Com isso espera-se possibilitar um melhor cenário futuro perante a disponibilidade deste recurso, crescimento demográfico e preservação ambiental.

\section{SISTEMA DE CAPTAÇÃO PLUVIAL, DIMENSIONAMENTO E INSTALAÇÃO}

Um sistema de captação, armazenagem e uso pluvial é caracterizado pela coleta de água da chuva, armazenamento da água coletada e uso desta para finalidades desejadas. O sistema é basicamente compreendido pela superfície de coleta, tubulações e interações, como um filtro, que a levem ao recipiente de armazenamento, geralmente uma caixa de água e, desta, tubulações que conduzem ao destino pretendido, como torneiras e bacias sanitárias.

Conforme o Manual do IPT (IPT, 2015) e Tomaz (2003), os principais componentes, usados genericamente, para a captação e uso de água da chuva são:

- Superfície de captação: Geralmente compreendendo os telhados das casas, indústrias ou edifícios, podendo possuir revestimento de telhas (tipo cerâmicas, fibrocimento, ferro galvanizado, entre outras) ou serem constituídos por lajes (revestidas com pisos, concreto etc.).

- Calhas e condutores: Para a captação e condução da água da chuva, podendo ser feitos de PVC ou metal.

- By Pass: Correspondendo a um sistema de descarte, manual ou automático, da primeira lavagem da superfície de captação pela chuva, limpando a sujeira mais grossa, acumulada.

- Filtro: Para remoção de partículas em suspensão.

- Reservatório: Recipiente de armazenamento para a água coletada, podendo estar elevado, apoiado, semienterrado ou enterrado, sendo construído de alvenaria, concreto armado, plástico, poliéster, entre outros. 
- Extravasor: Responsável por evitar o transbordamento do reservatório, liberando o excesso de água por este elemento (ladrão). Este deve possuir proteção para evitar a entrada de pequenos animais no reservatório.

Com o correto dimensionamento e instalação dos componentes do sistema de captação, armazenagem e uso de água da chuva é possível alcançar valores de economia de água potável até 38\% (SILVA; SOUSA; CARVALHO, 2015).

Para o dimensionamento do sistema de captação de água da chuva deve-se seguir a recomendação de Ghisi (2006), que adverte para a necessidade de análise independente a cada caso de implementação, tendo em vista que existem vários fatores que influenciam em seu dimensionamento. Assim, não existindo um tamanho predefinido, este deve ser avaliado a cada local de coleta. No Brasil, para o dimensionamento do sistema, deve-se seguir a ABNT NBR 15.527 (ABNT, 2007), que trata do aproveitamento de água de chuva de coberturas em áreas urbanas, para fins não potáveis.

Os passos de dimensionamento e instalação, dispostos na sequência, são baseados nas Normas brasileiras (NBR) e na literatura de Tomaz (2003).

\subsection{Metodologia de cálculo e dimensionamento}

Para uma correta concepção do sistema, alguns fatores devem ser levados em conta, dentre estes os mais importantes são o consumo de água na edificação, a área disponível para captação pluvial, as calhas e condutores do sistema, o coeficiente de Runoff (representativo do escoamento superficial de lavagem) e o recipiente de armazenamento da água captada. Estes fatores serão necessários para o desenvolvimento do projeto de um protótipo para coleta, tratamento e armazenamento de água de chuva, proposto neste trabalho.

A elaboração do projeto deve ser baseada na norma referente à instalação predial de água fria, ABNT NBR 5.626 (ABNT, 1998) e de instalações prediais de água pluvial, ABNT NBR 10.844 (ABNT, 1989), devendo ainda apresentar a quem e para o que se destina o uso da água pluvial, bem como estimar sua demanda. Para o dimensionamento, séries históricas de precipitação devem ser estudadas, estando disponíveis em fontes como a Hidroweb (ANA, 2019), site com dados fornecidos pela Agência Nacional de Águas (ANA), ou Nurma (SENTELHAS et al., 2009), site com as precipitações históricas fornecidas pelo IPT da USP.

A seguir está descrita a metodologia para o cálculo e dimensionamento de um sistema de coleta e armazenagem de água pluvial, sendo apresentadas as considerações para determinação do consumo residencial, a área de captação a ser considerada, o coeficiente de lavagem inicial ou Runoff, o armazenamento e o bombeamento, quando necessário. Para o cálculo de armazenamento usou-se o método de Rippl que permite uma análise gráfica ou analítica. Neste trabalho utilizou-se a análise de forma analítica, a qual será mostrada adiante.

\subsubsection{Consumo}

O consumo de água em litros por habitante por dia é variável, dependendo da localização nas regiões do Brasil, devendo ser analisada especificamente a localidade pretendida para a instalação do sistema. O Sistema Nacional de Informações sobre o Saneamento (SINS, 2018) apresenta os dados do consumo de água médio per capita por regiões do país, sendo: 
- 182,6 I/hab.dia na região Sudeste;

-158,8 I/hab.dia na região Centro-Oeste;

- 154,2 I/hab.dia na região Norte;

-153,6 I/hab.dia na região Sul; e

- 115,4 l/hab.dia na região Nordeste.

Com o consumo médio per capita é possível se estimar as finalidades de uso e, assim, a quantidade de água destinada a funções que não demandem potabilidade. O gasto de água potável em uma residência, proveniente de distribuição pública, pode ser subdividido da seguinte maneira (SILVA; SOUSA; CARVALHO, 2015):

- $39 \%$ em chuveiros;

- $1 \%$ em lavagem de louças;

- $14 \%$ em torneiras;

- $8 \%$ na pia da cozinha;

- 29\% em descargas sanitárias;

- $8 \%$ em máquina de lavar; e

- $1 \%$ em usos externos.

Levando em conta estes consumos médios de água em residências, é possível verificar que deste total, em cerca de $38 \%$ não haveria necessidade do consumo de água potável, isto é, no uso em descargas sanitárias (29\%), máquinas de lavar (8\%) e usos externos (1\%).

\subsection{2 Área de captação pluvial}

A área de captação pluvial corresponde à superfície de onde se pretende aproveitar a incidência de chuva, sendo representada pela sua projeção horizontal, através da qual, com os índices pluviométricos de séries históricas, consegue se estimar a quantidade de água passível de ser obtida. O volume captado pode ser estimado pela Equação 1.

$$
\mathrm{Vc}=\mathrm{Ac} \times \mathrm{I} \times 10^{-3}
$$

Em que:

$\mathbf{V}_{\mathbf{c}}=$ volume captado $\left(\mathrm{m}^{3}\right)$;

$A_{c}=$ área da seção do tanque de sedimentação $\left(m^{2}\right)$;

$\mathbf{I}=$ altura do nível de água $(\mathrm{mm})$.

\subsubsection{Calhas e condutores}

O dimensionamento das calhas e condutores deverá seguir as especificações da NBR 10.844 (ABNT, 1989), sobre as instalações prediais de água pluvia, possuindo dimensões mínimas e, no caso das calhas, inclinação mínima não sendo menor do que $0,5 \%$.

A vazão de projeto na calha é determinada pela área superficial de captação e pela intensidade pluviométrica, como se vê na Equação 2. 


$$
Q=[\mathrm{I} \times \mathrm{A}] \div 60
$$

Em que:

$\mathbf{Q}=$ vazão de projeto (L/min);

$\mathbf{I}=$ intensidade pluviométrica $(\mathrm{mm} / \mathrm{h})$;

$A=$ área de contribuição $\left(\mathrm{m}^{2}\right)$.

Os condutores pluviais podem ser constituídos de uma grande variedade de materiais, sendo a cada um deles atribuído um valor para o coeficiente de rugosidade de Manning. Este valor pode ser encontrado em tabelas, manuais e descritivos de produtos, fornecidos por seus fabricantes e pela literatura, como, por exemplo, na publicação da ABTC (2004), onde encontram-se valores de coeficiente de Manning para tubos de plástico PVC, variando de 0,009 em laboratório até 0,012 para o caso de projeto de drenagem. Há, porém, que se observar as características específicas do material a ser utilizado em cada caso. A fórmula de Manning é descrita na Equação 3, a seguir.

$$
Q=60000 \times[\mathrm{A} \div \mathrm{n}] \times\left[\mathrm{Rh}^{2 / 3}\right] \times \mathrm{S}^{1 / 2}
$$

Em que:

$$
\begin{aligned}
& \mathbf{Q}=\text { vazão de projeto }(\mathrm{L} / \mathrm{min}) ; \\
& \mathbf{A}=\text { área de seção molhada }\left(\mathrm{m}^{2}\right) ; \\
& \mathbf{R h}=A / P=\text { raio hidráulico }(\mathrm{m}) ; \\
& \mathbf{P}=\text { perímetro molhado }(\mathrm{m}) ; \\
& \mathbf{n}=\text { coeficiente de rugosidade de Manning; } \\
& \mathbf{S}=\text { declividade }(\mathrm{m} / \mathrm{m}) .
\end{aligned}
$$

Através da vazão de projeto, do coeficiente de Manning e das especificações do fabricante, escolhem-se as calhas e as tubulações mais adequadas ao sistema.

\subsubsection{Coeficiente de Runoff}

Como na maioria das vezes a superfície de coleta fica à mercê do tempo, poluentes, animais e outros fatores, adota-se um coeficiente de descarte, correspondendo à quantidade de água da chuva que deve ser jogada fora e a esta é atribuída a função de lavagem do telhado ou semelhante. Posteriormente a isso pode-se realizar a coleta pluvial com maior segurança.

O valor mais indicado para este coeficiente é de 0,8 , representando que $20 \%$ da água deve ser descartada, proporcionando a limpeza da superfície de coleta, e $80 \%$ pode ser aproveitada e armazenada. A esta porcentagem se dá o nome de coeficiente de Runoff.

\subsubsection{Armazenagem}

Para o dimensionamento volumétrico do recipiente de armazenagem se utilizará, neste caso, o método de Rippl. Este método consiste num estudo como "diagrama de massas", garantindo o abastecimento de água necessário ao consumo, mesmo em períodos de seca. Para este trabalho, utilizou-se a metodologia analítica, explicitada a seguir.

\subsubsection{Método analítico}


Esta metodologia é realizada com a construção de uma tabela (Tabela 1) contendo 8 colunas com informações pluviométricas, e analisando os valores obtidos.

TABELA 1: Dimensionamento do reservatório pelo método analítico de Rippl

\begin{tabular}{cccccccc}
\hline 1 & $\mathbf{2}$ & $\mathbf{3}$ & $\mathbf{4}$ & $\mathbf{5}$ & $\mathbf{6}$ & $\mathbf{7}$ & $\mathbf{8}$ \\
\hline Meses & $\begin{array}{c}\text { Chuva } \\
\text { média } \\
\text { mensal } \\
(\mathrm{mm})\end{array}$ & $\begin{array}{c}\text { Demanda } \\
\text { constante } \\
\text { mensal }\left(\mathrm{m}^{3}\right)\end{array}$ & $\begin{array}{c}\text { Área de } \\
\text { captação } \\
\left(\mathrm{m}^{2}\right)\end{array}$ & $\begin{array}{c}\text { Volume de } \\
\text { chuva } \\
\text { mensal }\left(\mathrm{m}^{3}\right)\end{array}$ & $\begin{array}{c}\text { Diferença } \\
\text { entre } \\
\text { demanda e } \\
\text { chuva }\left(\mathrm{m}^{3}\right)\end{array}$ & $\begin{array}{c}\text { Diferença } \\
\text { acumulada } \\
\text { positiva }\left(\mathrm{m}^{3}\right)\end{array}$ & Observação \\
\hline
\end{tabular}

Jan.

$\cdots$

Dez.

Fonte: Autores (2018)

- Coluna 1: É o período de 1 ano, compreendendo linhas de janeiro a dezembro;

- Coluna 2: Chuvas médias mensais em milímetros da localidade em questão;

- Coluna 3: Consumo mensal de água para finalidades não potáveis, em metros cúbicos;

- Coluna 4: A projeção horizontal da área de captação pluvial, em metros quadrados;

- Coluna 5: Volumes disponíveis de água de chuva mensalmente, em metros cúbicos. Os valores desta coluna são obtidos multiplicando-se os valores da coluna 2 , da coluna 4 e do coeficiente de Runoff $(0,8)$, por fim divide-se o resultado por 1000 ;

- Coluna 6: Esta coluna expressa a diferença entre o volume de consumo e o volume captado com as chuvas mensais, em metros cúbicos. É calculada pela subtração da coluna 3 pela 5; os resultados negativos indicam excesso de água captada, enquanto os positivos indicam que há falta ou redução;

- Coluna 7: Esta coluna representa a soma acumulada dos valores positivos da coluna 6, assumindo o reservatório cheio e descartando os valores negativos; e

- Coluna 8: Esta coluna é preenchida com E (água escoando pelo ladrão), D (nível de água baixando) e $S$ (Nível de água subindo), representando apenas um indicativo.

Deste modo, consegue-se dimensionar o volume do reservatório de acordo com o valor máximo acumulado, obtido na coluna 7.

\subsubsection{Bombeamento}

Dependendo da situação e alocação do reservatório, uma bomba para elevação da água coletada a outro reservatório pode ser necessária. Nestes casos é recomendado seguir os dados do produto garantidos pelo fornecedor e se estudar a perda de carga proveniente da tubulação por onde ocorrerá a elevação, garantindo, assim, a funcionalidade deste processo.

\subsection{Recomendações}

Para um melhor funcionamento do sistema de coleta, armazenagem e uso pluvial, uma série de técnicas e tecnologias podem ser aplicadas; dentre estas, as mais importantes são as que seguem. 
- Reservatório de autolimpeza: O primeiro escoamento pluvial sobre um telhado é responsável por levar a poeira, fezes de pássaros e animais, folhas e detritos, e a primeira parte dessa água, a que leva toda esta sujeira, recebe o nome de First Flush (TOMAZ, 2003). Dentro do conceito de Runoff, o First Flush prevê o descarte de $2 \mathrm{~mm}$ de precipitação, correspondente aproximadamente aos primeiros 10 minutos da chuva. Assim, um reservatório de autolimpeza para estes $2 \mathrm{~mm}$ pode ser projetado, evitando-se perdas de água desnecessárias.

- Filtro volumétrico: Filtro separador dos detritos carreados no Runoff, separando a água da chuva que se deseja coletar do particulado grosseiro. Seu funcionamento por gravidade e peneiramento proporcionam uma autolimpeza do sistema e limpeza contínua da água. Em seu processo existe a perda de aproximadamente $5 \%$ da água, excluída juntamente com os resíduos sólidos.

- Cloração: Para um maior controle microbiológico, pode-se realizar a adição de cloro ao sistema, prevenindo a procriação de colônias de algas e bactérias.

- Tubulação distinta: Com o uso de um sistema de coleta, armazenagem e uso de água pluvial, novas tubulações devem ser instaladas, servindo a demanda do consumo desta água. Porém, esta nova tubulação não deve ser confundida com a já existente de água potável, devendo, portanto, haver uma distinção entre as duas, geralmente indicada por cores distintas no encanamento.

\subsection{Manutenção}

Para a garantia do funcionamento do sistema pluvial, tanto mecânico como biológico, devem ser realizadas averiguações periódicas quanto a sua estanqueidade física e quanto ao acúmulo de sedimentos em seus reservatórios.

Os reservatórios, ou o reservatório de limpeza, caso esteja sendo usado, acumulam lodo no fundo, proveniente de partículas finas que passaram pelo first flush (início do Runoff) e filtro. Este lodo deve ser retirado, efetuando periodicamente, ou quando constatada sua presença, limpeza dos reservatórios. Este procedimento é muito importante, pois evita a procriação de algas, bactérias e até amebas na água do reservatório.

Também é importante a limpeza periódica, ou quando se constatar necessário, do filtro, mantendo sua funcionalidade, evitando entupimentos e prevenindo a procriação de colônias de algas e bactérias em seu interior.

\section{SIMULAÇÃO DE USO DE ÁGUA PLUVIAL NA FAMÍLIA PAULISTANA}

O tamanho médio da família paulistana é de 3,2 pessoas (IBGE, 2008) e o consumo médio por habitante na região Sudeste é de 182,6 I/hab.dia (SINS, 2018). Com isso é possível estimar o volume de água médio consumido pela família a cada mês, representando o total de 17.529,60 I/mês.

Deste montante consumido mensalmente pelos integrantes da família, sabe-se que aproximadamente $38 \%$ se destinam a usos que não demandam potabilidade (SILVA; SOUSA; CARVALHO, 2015), gerando uma demanda mensal de 6.661,25 l/mês. Com estes dados, com as precipitações médias mensais de dados históricos da Nurma (SENTELHAS et al., 2009) com a sequência metodológica descrita neste trabalho e com uma superfície de coleta de chuva de 100 
$\mathrm{m}^{2}$, se efetuou o dimensionamento do reservatório de armazenagem pluvial pelo método de Rippl, como está disposto na Tabela 2.

TABELA 2: Dimensionamento do reservatório pelo método analítico de Rippl

\begin{tabular}{|c|c|c|c|c|c|c|c|}
\hline Meses & $\begin{array}{l}\text { Chuva } \\
\text { média } \\
\text { mensal } \\
\text { (mm) }\end{array}$ & $\begin{array}{l}\text { Demanda } \\
\text { constante } \\
\text { mensal }\left(\mathrm{m}^{3}\right)\end{array}$ & $\begin{array}{l}\text { Área de } \\
\text { captação } \\
\left(\mathrm{m}^{2}\right)\end{array}$ & $\begin{array}{l}\text { Volume de } \\
\text { chuva } \\
\text { mensal }\left(\mathrm{m}^{3}\right)\end{array}$ & $\begin{array}{c}\text { Diferença } \\
\text { entre } \\
\text { demanda e } \\
\text { chuva }\left(\mathrm{m}^{3}\right)\end{array}$ & $\begin{array}{c}\text { Diferença } \\
\text { acumulada } \\
\text { positiva }\left(\mathrm{m}^{3}\right)\end{array}$ & Observação \\
\hline Jan. & 234 & 6,66 & 100 & 23,40 & $-16,74$ & & $E$ \\
\hline Fev. & 231 & 6,66 & 100 & 23,10 & $-16,66$ & & $\mathrm{E}$ \\
\hline Mar. & 165 & 6,66 & 100 & 15,50 & $-8,84$ & & $E$ \\
\hline Abr. & 69 & 6,66 & 100 & 6,90 & $-0,24$ & & $E$ \\
\hline Mai. & 51 & 6,66 & 100 & 5,10 & 1,56 & 1,56 & $\mathrm{D}$ \\
\hline Jun. & 44 & 6,66 & 100 & 4,40 & 2,26 & 3,82 & $\mathrm{D}$ \\
\hline Jul. & 35 & 6,66 & 100 & 3,50 & 3,16 & 6,98 & $\mathrm{D}$ \\
\hline Ago. & 32 & 6,66 & 100 & 3,20 & 3,46 & 10,44 & $\mathrm{D}$ \\
\hline Set. & 63 & 6,66 & 100 & 6,30 & 0,36 & 10,80 & $\mathrm{D}$ \\
\hline Out. & 128 & 6,66 & 100 & 12,80 & $-6,14$ & & $S$ \\
\hline Nov. & 123 & 6,66 & 100 & 12,30 & $-5,64$ & & $\mathrm{~S}$ \\
\hline Dez. & 180 & 6,66 & 100 & 18,00 & $-11,34$ & & $\mathrm{~S}$ \\
\hline
\end{tabular}

Fonte: Autores (2018).

Como observado na Tabela 2, o volume necessário ao reservatório é de $10,80 \mathrm{~m}^{3}$, atendendo assim a família média paulistana e, com este volume, sendo capaz de armazenar e suprir água suficiente às demandas durante todo o ano, resguardando o uso potável a utilidades mais nobres.

\subsection{Custo-beneficio}

Um reservatório de fibra de vidro com capacidade para $10 \mathrm{~m}^{3}$ está na faixa de preço de U\$ 653,70 (ACQUAFORT, 2019b), um reservatório menor, de $1 \mathrm{~m}^{3}$ para prover o uso diário do telhado da casa, está por volta de U\$ 57,24 (ACQUAFORT, 2019a). Somando-se a estes o custo de uma bomba, instalações prediais e mão de obra, encontra-se um valor próximo de U\$1.996,40.

Segundo as tarifas da SABESP (2019), antes da implementação do sistema de captação, armazenagem e uso pluvial, a conta de água e esgoto fica em U\$ 28,70, já com a implementação o valor cai para U\$ 19,57, gerando uma economia mensal de U\$ 9,13, acarretando em um ano a quantia de U\$ 109,56 poupados.

É possível perceber que a implementação deste sistema proporciona um custo benefício de retorno lento, necessitando de aproximadamente 18 anos para o retorno do investimento inicial realizado. 
Contudo, a utilização do sistema se mostra viável perante ao impacto ambiental, poupando água potável e preservando mananciais, faltando então, uma política de incentivo eficiente a sua difusão no meio urbano.

\subsection{Simulação de coleta, armazenagem e uso pluvial difundidos}

Segundo a Secretaria Municipal de desenvolvimento Urbano (SMDU, 2019), no município de São Paulo existe uma área residencial com construções horizontais equivalentes a $165.161 .896 \mathrm{~m}^{2}$, estas estando distribuídas num total de 1.282.094 lotes. Estes dados estão distribuídos da seguinte forma:

- Uso residencial horizontal baixo padrão: Área construída de 57.939.471 m² em 639.489 lotes;

- Uso residencial horizontal médio padrão: Área construída de 88.257 .457 m² em 588.733 lotes; e

- Uso residencial horizontal alto padrão: Área construída de $18.964 .968 \mathrm{~m}^{2}$ em 53.872 lotes.

Conforme a precipitação média mensal de 112,9 mm (SENTELHAS et al., 2009), consegue-se determinar o volume de captação e utilização de água da chuva, como descrito no caso de implementação do tópico 4 , porém, se extrapolando para todas as residências horizontais do município de São Paulo. Assim, para o total de residências horizontais, captando água da chuva numa área equivalente a sua área construída, obtêm-se um volume captado de $18.646 .778 \mathrm{~m}^{3}$ contra o uso não potável de $8.538 .746 \mathrm{~m}^{3}$, resultando em volume pluvial captado excedente, demonstrando, portanto, eficiência na aplicação.

Observa-se que com o volume de $18.646 .778 \mathrm{~m}^{3}$ captado, poderia se armazenar mensalmente um volume equivalente a $1,89 \%$ do volume $982.070 .000 \mathrm{~m}^{3}$, este sendo o volume total de trabalho do sistema Cantareira (SABESP, 2016). Com isso, é possível observar que em um ano, uma quantia próxima de $23 \%$ do volume máximo do Cantareira pode ser economizada.

\section{PROPOSTA DE DESENVOLVIMENTO DE PROTÓTIPO}

\subsection{Protótipo}

Com os resultados da simulação, decidiu-se desenvolver um protótipo de coleta e melhoramento da água pluvial, para assim, alcançar um uso doméstico mais seguro e eficiente. Como a maioria dos componentes de um sistema de coleta, armazenagem e uso pluvial são estritamente dependentes da localidade de aplicação, como o reservatório, as calhas, as tubulações e a superfície de coleta, um sistema de tratamento e limpeza, ligando estes componentes e proporcionando o seu correto funcionamento foi desenvolvido.

Este sistema é basicamente composto por um filtro volumétrico, um tanque de decantação com cloração e uma bomba elevatória, como a disposição esquemática da Figura 1.

Procurou-se elaborar um produto com forma compacta, de fácil manutenção e utilização, onde se faz necessário apenas a conexão com os encanamentos de coleta e elevação da água pluvial, bem como a limpeza do tanque de decantação, após eventos de chuva ou quando se constatar necessário. 
Este sistema foi projetado, a princípio, para superfícies de coleta de $100 \mathrm{~m}^{2}$, suficiente ao uso médio familiar paulistano, possuindo dimensões de aproximadamente $1 \mathrm{~m}$ de altura por $1 \mathrm{~m}$ de diâmetro. Porém, suas dimensões podem ser alteradas, servindo assim a uma infinidade de áreas de captação distintas. Sua forma base pode ser vista na Figura 2.

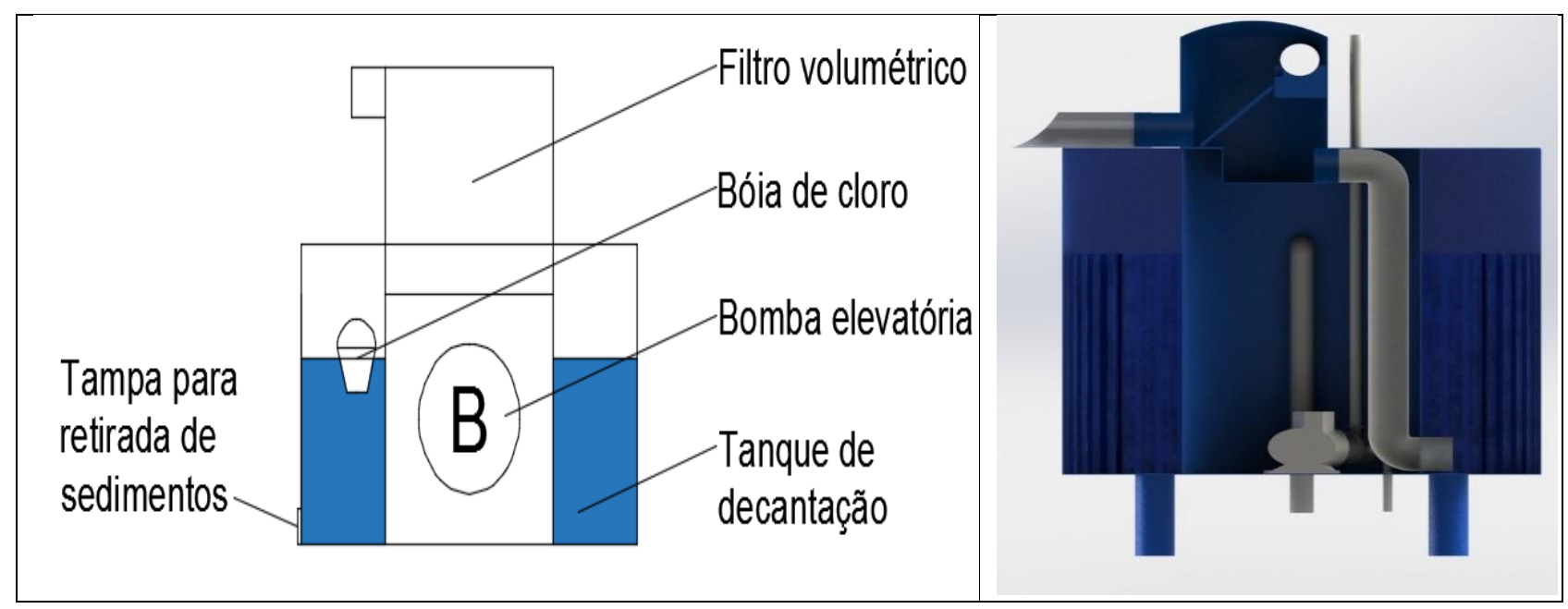

Fonte: Autores (2016).

FIGURA 1: Componentes principais do sistema pluvial.

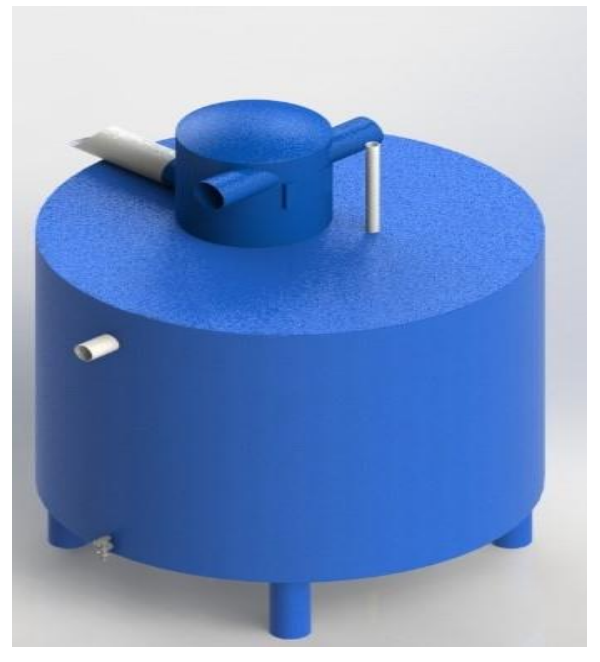

PERSPECTIVA

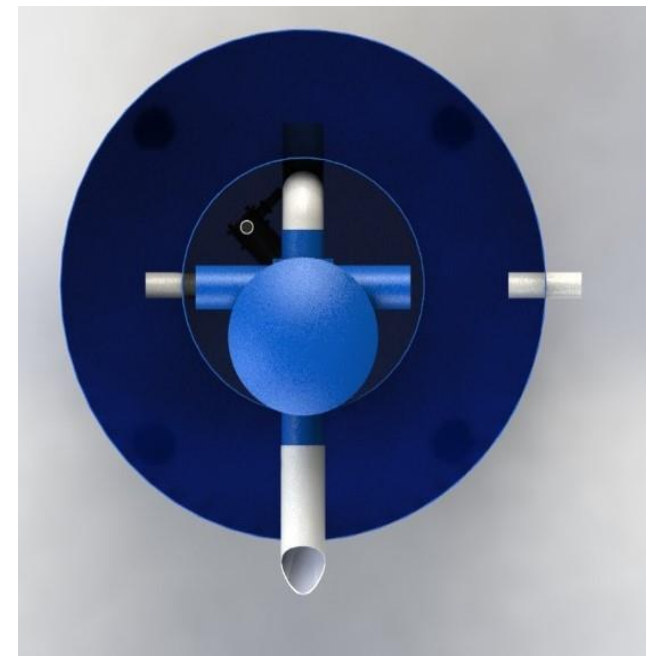

VISTA SUPERIOR

Fonte: Autores (2019).

FIGURA 2: Forma do sistema pluvial.

As etapas e seus processos estão descritos nos tópicos a seguir, listados de 1 a 4 , conforme é visto na Figura 3, detalhando o seu funcionamento.

1. A água pluvial captada do telhado é conduzida, através das calhas e tubulações, até a entrada do filtro volumétrico, onde por gravidade é separada do particulado grosseiro, 
passando por uma inclinação de lâminas sobre uma peneira. Assim, excluindo a água com sujeira (aproximadamente $5 \%$ ) e retendo a água mais limpa, que escoa até o tanque de decantação;

2. No tanque de decantação, a água fica retida e seu nível começa a subir, acalmando a turbulência inicial e, ao mesmo tempo, a boia de cloro dissolve sua pastilha, eliminando eventuais possibilidades de proliferação de algas e bactérias, mantendo a água límpida;

3. Com o tempo, o particulado fino que ainda havia sido carreado pela água precipita e se deposita no fundo do tanque de decantação. Assim, quando a água atinge a altura de entrada da tubulação de saída, sem sujeiras e partículas pequenas que estão dispostas no fundo do tanque, flui apenas a água superficial, mais limpa, para o reservatório principal; e

4. Captando do reservatório principal, através de mangueira com boia, mais uma vez retirando apenas a água superficial, uma bomba de elevação remaneja a água de demanda diária, a fim de suprir um reservatório menor, disposto no telhado que, por sua vez, distribuirá a água aos pontos de usos não potáveis da edificação.
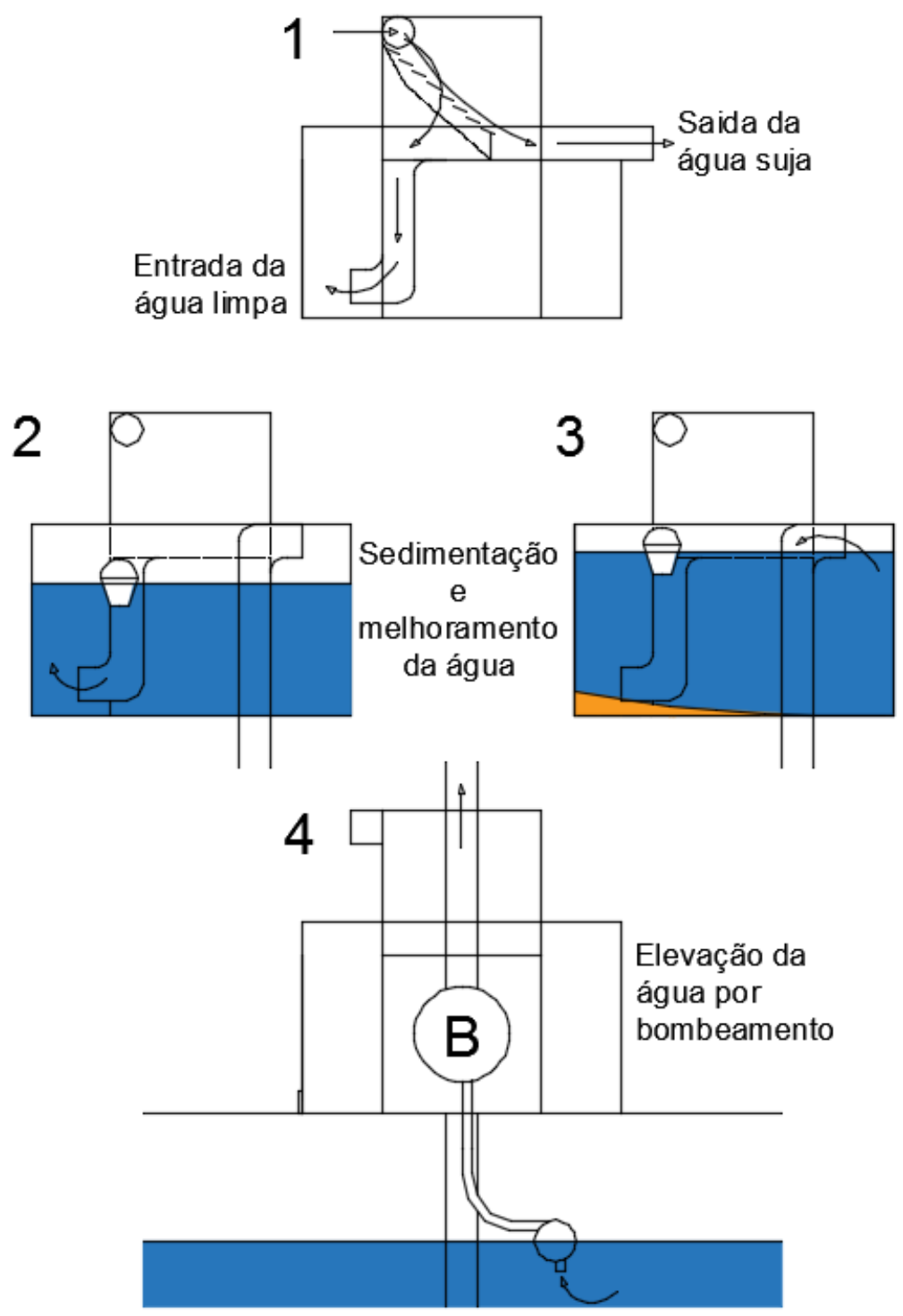

Fonte:Autores (2016). 
FIGURA 3: Etapas de tratamento e caminho da água.

Este protótipo foi montado e testado na Faculdade de Engenharia de Guaratinguetá (FEG) - UNESP, seus dados e resultados estão dispostos a seguir.

\subsection{Resultados de funcionamento}

O protótipo de coleta e tratamento de água pluvial foi construído em uma versão piloto para testes com a água coletada e análise de viabilidade de uso em residências. A Figura 4 apresenta o protótipo, como construído, e, a seguir, os resultados obtidos com a coletas realizadas.

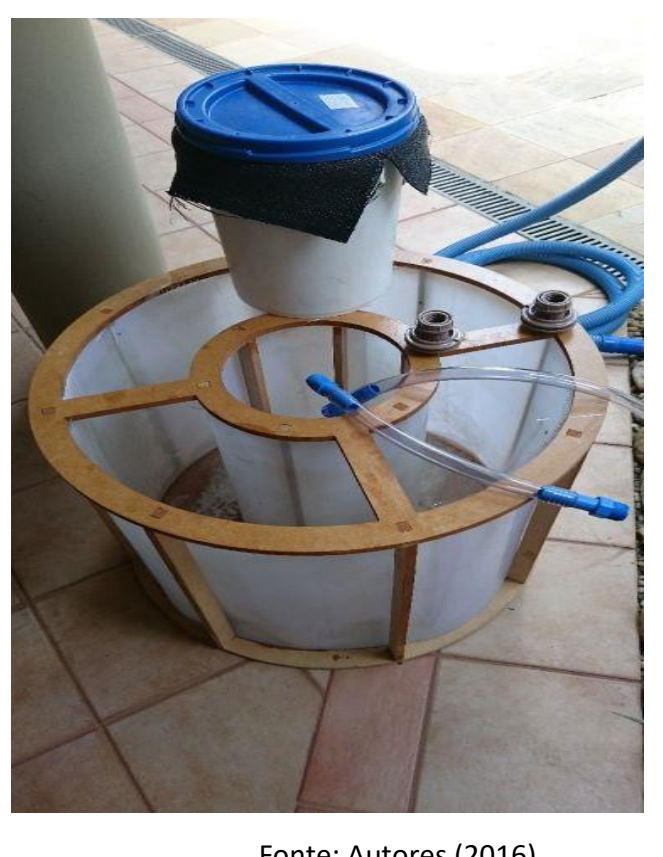

FIGURA 4: Protótipo em versão piloto.

Sabe-se que, segundo a NBR 15.527 (ABNT, 2007), uma solução de uso de água pluvial em uma residência deve atender a certos parâmetros de qualidade, garantindo uma boa salubridade e não oferecendo riscos aos usuários. Assim, análises quanto a coliformes totais, turbidez, cloro, cor aparente e pH da água pluvial coletada, antes e após o tratamento, foram realizadas e estão apresentados na Tabela 3.

TABELA 3: Dados de análise da água

\begin{tabular}{|c|c|c|c|c|c|}
\hline Análise & $\begin{array}{c}\text { Coliformes } \\
\text { totais } \\
\text { (UFC/100ml) }\end{array}$ & $\begin{array}{c}\text { Turbidez } \\
(\mu T)\end{array}$ & $\begin{array}{c}\text { Cloro } \\
\left(\mathrm{mg} / \mathrm{I}^{-1}\right)\end{array}$ & $\begin{array}{c}\text { Cor } \\
\text { Aparente } \\
(-)\end{array}$ & $\begin{array}{c}\mathrm{pH} \\
(\mu \mathrm{H})\end{array}$ \\
\hline $\begin{array}{c}\text { Água bruta } \\
(01 / 12 / 2017)\end{array}$ & 0,00 & 1,05 & 0,00 & 0,00 & 6,30 \\
\hline $\begin{array}{l}\text { Água tratada } \\
(01 / 12 / 2017)\end{array}$ & 0,00 & 0,54 & 0,00 & 0,00 & 6,20 \\
\hline $\begin{array}{c}\text { Água bruta } \\
(02 / 02 / 2018)\end{array}$ & 0,00 & 1,12 & 0,00 & 0,00 & 6,20 \\
\hline $\begin{array}{l}\text { Água tratada } \\
(02 / 02 / 2018)\end{array}$ & 0,00 & 0,66 & 0,00 & 0,00 & 6,20 \\
\hline $\begin{array}{c}\text { Água bruta } \\
(03 / 03 / 2018)\end{array}$ & 0,00 & 1,14 & 0,00 & 0,00 & 6,10 \\
\hline
\end{tabular}




\begin{tabular}{llllll}
\hline $\begin{array}{l}\text { Água tratada } \\
(03 / 03 / 2018)\end{array}$ & 0,00 & 0,69 & 0,00 & 0,00 & 6,00 \\
\hline
\end{tabular}

Fonte: Autores (2018).

Destes resultados observa-se que há melhora significativa na qualidade da água, embora até mesmo a água da chuva sem tratamento já seria considerada como segura para o uso doméstico não potável (ABNT, 2007).

Ressalta-se que, apesar de ser realizada a cloração, a água final tratada não possui qualquer sinal do produto usado. Isto devido à alta volatilidade do Cloro, que é perdido da água para o ar no processo.

\subsection{Discussão}

A utilização de sistemas de captação e tratamento de água pluvial tem possibilidade de gerar economia na retirada de água dos mananciais, diminuindo o volume de água a ser tratado em estações de tratamento. Consequentemente, diminui-se a produção de resíduos gerados neste processo e possibilita-se, finalmente, uma revitalização dos corpos hídricos. Apesar desta aplicação acarretar em grandes vantagens ambientais, seu custo e instalação representam uma quantia considerável à população, se pagando em longo período, sendo então, de difícil difusão e aplicação.

Devido a possibilidades econômicas e ambientais, resguardadas até então ao governo e órgãos competentes, um incentivo do uso pluvial deveria ser proposto, fomentando o interesse da população, através de vantagens fiscais ou auxílio na implementação do sistema. Deste modo, parte da demanda hídrica, que aceita a não potabilidade, seria provida pelos próprios cidadãos, deixando ao governo apenas a obrigação de demanda potável. Com isto, muitas vantagens poderiam ser conquistadas, como o alívio das concessionárias provedoras de água, diminuição da retirada de água de corpos hídricos e alívios monetários nas contas de água e luz.

\section{CONCLUSÃO}

A questão da gestão do uso da água é uma preocupação mundial, mediante a problemática apresentada em vários países quanto ao desperdício ou até escassez deste recurso natural. Por meio deste estudo pôde-se perceber que o uso da água pluvial acarreta diversas vantagens, neste sentido, poupando mananciais e melhorando situações causadas pela impermeabilização excessiva e ocupação indevida do solo, possibilitando a prevenção da falta de água e enchentes em meio urbano. Cuidados, porém, devem ser tomados com o uso desta água, garantindo uma correta instalação e manutenção do sistema de coleta, armazenagem e uso, destinando sua água a finalidades pertinentes, que não demandem potabilidade.

Neste trabalho avaliou-se o desenvolvimento de um sistema de captação, tratamento e uso pluvial genérico, com o objetivo de apresentar um protótipo criado, baseado em normas e metodologias relacionadas à instalação de água em residências urbanas, favorecendo a coleta, tratamento e armazenagem de água pluvial para uso familiar. Basicamente um sistema é composto pela superfície de coleta, tubulações e interações, até um recipiente de armazenamento, geralmente uma caixa de água, e tubulações que conduzem ao destino pretendido, como torneiras e bacias sanitárias.

A metodologia de cálculo para cada parte do sistema foi apresentada, bem como o dimensionamento para a reserva de água pluvial para fins onde a potabilidade não é exigida, 
garantindo o abastecimento anual para uma família considerada padrão em São Paulo, simulando a economia de água potável para estes casos e o custo benefício alcançável.

Finalmente, a proposta para a construção de um protótipo de sistema de coleta e tratamento de água pluvial foi apresentada, visando sua efetivação e aplicação em residências urbanas, possibilitando ajustes para cada local e especificidade de uso.

Como análise de viabilidade, destaca-se que este projeto necessita de aproximadamente 18 anos para o retorno do investimento inicial realizado. Inicialmente, isto pode acarretar uma dificuldade de adoção pela maioria da população, a menos que haja incentivos para sua utilização.

Conclui-se que o sistema inovador proposto neste trabalho, sob a patente BR 102018008120 9, acarretará numa facilidade de difusão do sistema, tornando mais fácil sua instalação e utilização, assim, o uso de água da chuva ficará disponível a qualquer usuário. Avalia-se que esta iniciativa teria um impacto maior com o auxílio de programas públicos de incentivo, promovendo seu uso e traria todos os benefícios dispostos neste trabalho.

\section{AGRADECIMENTOS}

Agradecimento aos professores doutores Márcia Freitas e Daniel Silva pela ajuda e incentivo, também à Pró Reitoria de Pesquisa da UNESP - PROPe por ter tornado este trabalho, sob a forma de iniciação cientifica, possível (Edital ICSB/PROPE/UNESP edital 19/2015).

\section{REFERÊNCIAS BIBLIOGRÁFICAS}

ABNT. ASSOCIAÇÃO BRASILEIRA DE NORMAS TÉCNICAS. NBR 5.626: Instalação predial de água fria. Rio de Janeiro: [s. n.], 1998

ABNT. ASSOCIAÇÃO BRASILEIRA DE NORMAS TÉCNICAS. NBR 10.844: Instalações prediais de águas pluviais. São Paulo: [s. n.], 1989.

ABNT. ASSOCIAÇÃO BRASILEIRA DE NORMAS TÉCNICAS. NBR 15.527: água de chuva:

aproveitamento de coberturas em áreas urbanas para fins não potáveis: requisitos. São Paulo: [s. n.], 2007.

ABTC. ASSOCIAÇÃO BRASILEIRA DOS FABRICANTES DE TUBOS DE CONCRETO. História da Pesquisa dos Valores do Coeficiente de Manning. São Paulo, 2004, 12p.

ACQUAFORT. Caixa D'água 1000 Litros Polietileno Fortlev. 2019a. Disponível em: https://www.acquafort.com.br/produto/1337/caixa-dagua-1000-litros-polietileno-fortlev. Acesso em 10 out. 2019.

ACQUAFORT. Caixa D'água Fibra de Vidro 10000 L C/ Tampa Bakof Tec. 2019b. Disponível em: https://www.acquafort.com.br/produto/1370/caixa-dagua-fibra-de-vidro-10000-I-c-tampa-bakoftec. Acesso em 10 out. 2019. 
ANA. AGÊNCIA NACIONAL DE ÁGUAS (Brasil). HidroWeb: sistemas de informações hidrológicas. Disponível em:<http://www.snirh.gov.br/hidroweb/apresentacao>. Acesso em: 31 out. 2019.

CAMPOS, M.A.S. Aproveitamento de água pluvial em edifícios residenciais multifamiliares na cidade de São Carlos. 2004. 145 f. Dissertação (Mestrado em Construção Civil) - Universidade Federal de São Carlos, São Carlos, SP. 2004.

COHIM, E.; GARCIA, A. P.; KIPERSTOK, A. Captação de água de chuva no meio urbano para usos não potáveis. In: SIMPÓSIO BRASILEIRO DE CAPTAÇÃO E MANEJO DE ÁGUA DE CHUVA, 6., 2007, Belo Horizonte. Anais... Belo Horizonte, 2007..

GHISI, E. Potential for potable water savings by using rainwater in the residential sector of Brazil. Building and Environment, Florianópolis, v. 41, 7 p., 2006.

IBGE, Sistema IBGE de Recuperação Automática - SIDRA. Tabela 1595 - Número de famílias e Tamanho médio da família por classes de rendimento total e variação patrimonial mensal familiar. 2008. Disponível em: https://sidra.ibge.gov.br/tabela/1595. Acesso em 13 out. 2019.

IPT - Instituto de Pesquisas Tecnológicas do Estado de São Paulo. Manual para captação emergencial e uso doméstico de água de chuva, 2015. Disponível em:

<http://www.ipt.br/noticia/905-passo_a_passo:_agua_de_chuva.htm> Acesso em 10 out. 2019.

JAQUES, R.C. Qualidade da água de chuva no município de Florianópolis e sua potencialidade para aproveitamento em edificações. 2005. 102 f. Dissertação (Mestrado em Engenharia Ambiental) - Universidade Federal de Santa Catarina, Florianópolis, SC. 2005.

MARTINS, A. et al. Sistema Cantareira e a crise de água em São Paulo: A falta de transparência no acesso a informação. 2014. Disponível em: <http://artigo19.org/blog/2014/12/11/relatoriosistema-cantareira-e-a-crise-da-agua-em-sao-paulo-a-falta-de-transparencia-no-acesso-ainformacao/>. Acesso em 01 ago. 2016.

OLIVEIRA FILHO, G.R. A crise da água na região metropolitana de São Paulo em 2014 e a ineficiente gestão dos recursos hídricos. CES Revista, Juiz de Fora, v. 29, n. 1. P. 5 a 20. 2015.

SABESP. Conheça as Nossas Tarifas. 2019. Disponível em:

https://www9.sabesp.com.br/agenciavirtual/pages/template/siteexterno.iface?idFuncao=13. Acesso em: 22 dez. 2019.

SABESP. Boletim mananciais. 2016. Disponível em:

http://site.sabesp.com.br/site/uploads/File/boletim/2016/boletim_manancia_02jul16.pdf. Acesso em: 20 ago. 2016.

SENTELHAS, P.C. et al. Balanços Hídricos Climatológicos do Brasil: $\mathbf{5 0 0}$ balanços hídricos de localidades brasileiras. Piracicaba: ESALQ, 2009. Disponível em:

http://www.leb.esalq.usp.br/leb/bhbrasil/. Acesso em: 06 out. 2019. 
SILVA C.M.; SOUSA V.; CARVALHO, N.V. Evaluation of Rainwater Harvesting in Portugal: Application Tom Single-Family Residences. Resources, Conservation and Recycling, v. 94, p. 21-34. 2015.

SINS - SISTEMA NACIONAL DE INFORMAÇÕES SOBRE SANEAMENTO. Diagnóstico dos serviços de água e esgoto - 2018. Ministério das Cidades, Secretaria Nacional de Saneamento ambiental. 2018. Disponível em:

http://www.snis.gov.br/downloads/diagnosticos/ae/2018/Diagnostico_AE2018.pdf. Acesso em: 10 out. 2019.

SMDU - Secretaria Municipal de Desenvolvimento Urbano. Relação de Área de Terreno, Área Construída e № de Lotes por Tipologia de Uso. 2019. Disponível em:

https://www.prefeitura.sp.gov.br/cidade/secretarias/upload/chamadas/at_ac_e_lotes_por_ut_20 19_1566938091.htm. Acesso em: 13 out. 2019.

TOMAZ, P. Aproveitamento de água de chuva: Aproveitamento de água de chuva para áreas urbanas e fins não potáveis. São Paulo: Editora Hermano \& Bugelli, 2003. 180 p.

TUCCI, C.E.M.; HESPANHOL, I.; NETTO, O.M.C. Gestão da Água no Brasil. Brasília: Edições UNESCO, 2001. $191 \mathrm{p}$.

USGS - UNITED STATES GEOLOGICAL SURVEY. How much water is there on, in, and above the Earth?, 2016. Disponível em: <http://water.usgs.gov/edu/earthhowmuch.html>. Acesso em 18 dez. 2019.

VIOLA, H.; NUNES, R. T. S.; FREITAS, M. A. V. Aproveitamento de águas pluviais como potencial ação mitigadora dos efeitos das mudanças climáticas: o caso da Cidade do Samba no Município do Rio de Janeiro. In: SIMPÓSIO BRASILEIRO DE RECURSOS HÍDRICOS, 17., 2007, São Paulo. Anais... São Paulo: [s.n.], 2007. 